\title{
Las plataformas de gobierno de ARENA y FMLN-USC
}

\author{
Centro de Información, Documentación \\ y Apoyo a la Investigación \\ $(C I D A I)^{l}$
}

Análisis de las plataformas políticas del partido ARENA y de la Coalición FMLN-USC. Una de las constataciones del artículo es que, en la recién pasada campaña electoral, se pasó de largo por lo que era lo más importante de ella: la discusión a fondo de las plataformas de gobierno. Los autores destacan la poca atención que se prestó a las plataformas en los medios de comunicación, así con el papel marginal que las mismas jugaron en la estrategias partidarias por atraer electores.

\section{Introducción}

Durante la recién finalizada campaña electoral predominaron, como en elecciones pasadas, los planteamientos políticos sin contenido; es decir, en lo absoluto se discutieron a fondo los principales problemas de El Salvador. Las exigencias del impacto publicitario se impusieron por sobre la discusión seria y profunda de los desafíos económicos, políticos y sociales que enfrenta nuestro país en vísperas de un nuevo milenio. Como ya es tradición, la campaña electoral estuvo marcada por las promesas de ocasión, esto es, por aquellas promesas que suelen hacer los políticos salvadoreños al calor de discursos retóricos y emotivos.

2. En la elaboración de este artículo participaron los siguientes miembros del CIDAI: Luis Armando González, Luis Romano, Marcel Vargas y Carmen Elena Villacorta 
En el mar de ofrecimientos destinados a convencer a los ciudadanos de que su felicidad estaba en manos de quien en ese momento se dirigía a ellos, se pasó de largo por lo que, en definitiva, era lo más importante de la campaña electoral: las plataformas de gobiemo y su discusión a fondo. Poca atención se prestó a esto en los medios de comunicación e incluso los mismos partidos hicieron de la discusión pública de sus plataformas algo marginal, cuando no inexistente, en su estrategia por atraer electores.

Las plataformas que más debieron atraer la atención pública fueron las de la coalición FMLNUSC y ARENA ${ }^{2}$, las dos agrupaciones políticas más importantes del país. Sin embargo, no fue así: ni hubo posibilidad de confrontarlas públicamente entre sí ni los candidatos a la presidencia por ambas instancias políticas se mostraron dispuestos - por incompetencia o negligencia - a discutir en detalle los supuestos de fondo de sus propuestas.

A lo más que llegó el candidato de ARENA, Francisco Flores, fue a proclamar ante diversos sectores sociales — sin capacidad de interlocusión alguna- las "alianzas" que sostienen su plataforma de gobierno. Al candidato de la coalición, Facundo Guardado, le fue sumamente difícil relacionar su proselitismo cotidiano con los ejes de su propuesta para el cambio. Una vez que el desenlace del evento electoral ha sido conocido, es conveniente prestar atención a lo más sustantivo de la campaña política que acaba de finalizar. El examen de la plataforma del FMLN-USC nos permitirá valorar hasta qué punto lo ofrecido por ella se distanciaba de la plataforma elaborada por ARENA. El examen de esta última, por su parte, nos permitirá tener en claro, con todas las implicaciones que eso pueda tener, por dónde ha ofrecido llevar al país la tercera administración de ARENA.

\section{Propuestas económicas}

Durante toda la década de 1990, El Salvador ha estado gobernado por el partido ARENA. Las políticas que éste ha implementado han sido de carácter neoliberal. Algunas de las medidas más importantes de los dos gobiemos de ARENA fueron la liberalización del comercio exterior, la eli- minación de los controles de precios, la privatización de empresas públicas (incluyendo las encargadas de las telecomunicaciones y la distribución de energía eléctrica), la reforma tributaria y la reforma del Banco Central de Reserva (BCR). Estas medidas han sido realizadas sin mayores contratiempos, gracias a la existencia de condiciones favorables para la estabilidad macroeconómica. El crecimiento económico ha oscilado entre el 3 y 7 por ciento, respectivamente; las reservas internacionales se han incrementado y la inflación se ha contenido. Sin embargo, estos resultados no son atribuibles a las políticas neoliberales de ARENA, pues los dos presidentes salidos de su seno más bien se han preocupado por administrar la relativa solvencia proporcionada por el flujo de remesas familiares.

Los problemas económicos que más demandan una pronta atención por parte de los gobiernos que desartollarán políticas públicas en el futuro son: la desarticulación entre los sectores financiero y agropecuario e industrial, los crecientes déficit de la balanza comercial, la permanencia del déficit fiscal, el lento crecimiento de las exportaciones, la escasa diversificación productiva y la dependencia de las remesas internacionales para sostener la estabilidad macroeconómica. Con el objeto de aportar elementos para el análisis de los partidos mayoritarios en esta coyuntura, se exponen a continuación los contenidos más importantes de las políticas económicas propuestas por los candidatos presidenciales de ARENA y la coalición FMLN-USC.

\subsection{ARENA: "Alianza por el trabajo"}

La propuesta de ARENA en el terreno económico se ha denominado "Alianza por el trabajo" $y$, según el plan de gobierno de ese partido, pretende "trasladar los beneficios del progreso a todos los salvadoreños" a través de la integración de los diferentes sectores económicos en inversiones productivas que contribuyan a generar "trabajo e ingresos, así como dinamizar y elevar la productividad de los sectores que absorben mayor empleo". La "Alianza" propone cuatro áreas por desarrollar: políticas sectoriales (desarrollo del sector agropecuario, desarrollo de la micro y pequeña empresa, promoción de exportaciones e inversiones y desa-

2. Ver Coalición para el Cambio FMLN-USC, Programa de Gobierno de Concertación Nacional, San Salvador, febrero de 1999; Francisco Flores, La nueva Alianza, San Salvador, 1999. Las referencias de este artículo están tomadas de ambos documentos. 
rrollo del sector construcción), políticas de apoyo a la productividad, Nuevo Modelo de "Relaciones Laborales" y "Salvadoreños en el Exterior: Socios del Desarrollo". Para cada una de las áreas se proponen medidas concretas que no se incluirán aquí por razones de espacio.

Dentro de las políticas sectoriales, el "Desarrollo del Sector Agropecuario" tiene como objetivos principales: $(a)$ mejorar el acceso a la tierra a través del financiamiento; $(b)$ propiciar una estructura de precios relativos más favorables; (c) suplir las necesidades de crédito del sector agropecuario; $(d)$ fomentar la agroindustria; $(e)$ estimular la reforestación y diversificación agropecuaria; y $(f)$ desarrollar un nuevo modelo de extensionismo agropecuario. El "Desarrollo de la micro y pequeña empresa" perseguiría como objetivos principales: $(a)$ incrementar la disponibilidad crediticia para este sector; (b) propiciar las alianzas productivas y comerciales; y $(c)$ ofrecer la capacitación y asistencia técnica necesarias. La "Promoción de exportaciones e inversiones" persigue: (a) diversificar la base exportadora; $(b)$ reducir el costo de penetración de mercados en el exterior; y (c) impulsar mecanismos de atracción de inversiones. El cuarto componente de las políticas sectoriales, el "Desarrollo del sector construcción", pretende: (a) crear condiciones financieras, legales, institucionales y operativas que agilicen la oferta y la demanda de la vivienda; y
La propuesta de ARENA en el terreno económico se ha denominado "Alianza por el trabajo"... La "Alianza" propone cuatro áreas por desarrollar: políticas sectoriales, políticas de apoyo a la productividad, Nuevo Modelo de "Relaciones Laborales" y "Salvadoreños en el Exterior: Socios del Desarrollo". rrollo" tiene como objetivos principales: (a) la apertura de espacios para los salvadoreños que viven fuera del país; $(b)$ la construcción de redes solidarias para fortalecer los vínculos comunitarios; y (c) la promoción de los lazos culturales que refuercen la identidad nacional. Esto contempla un fortalecimiento institucional y legal (asistencia a salvadoreños en el exterior en aspectos migratorios, de sufragio y de registro de personas).

\subsection{FMLN-USC: "Economía para todos"}

Esta propuesta económica "trata de construir las condiciones que amplíen las oportunidades que debe[n] de tener las grandes mayorías... en [la] calidad de sus vidas y las de sus familias", para lo cual se afirma que es prioritario pasar de una economía supeditada a los "intereses de los grupos financieros más poderosos, hacia una economía productiva, generadora de más y mejores empleos". Las grandes áreas de acción que se proponen son: "Más y mejor empleo", "Política fiscal", "Reforma del sistema financiero", "Desarrollo rural", "Política industrial", "Micro, pequeña y mediana empresa", "Formación de ahorro interno", "Asignación y regulación de las inversiones", "Protección al consumidor" $y$, finalmente, el "Desarrollo local". Debido a su importancia, en lo que sigue se reseñarán los contenidos principales de las primeras seis grandes áreas de políticas.

(b) proveer de infraestructura pública que sería ejecutada por el sector privado.

Los objetivos de "Más y mejor empleo" pretenden ser logrados, a corto plazo, a través de políticas de incremento de la inversión pública y de la creación de incentivos para empresarios que "contribuyan a incrementar el empleo o a mejorar los salarios". A largo plazo, los mayores niveles de empleo se conseguirían elevando la productividad, "facilitando" el mercado de trabajo y elevando la calidad del mismo. Esto último se lograría principalmente a través de la legislación laboral. La "Política fiscal", por otra parte, perseguiría el "mejoramiento de la productividad del gasto público", a través de la eficiencia en la recaudación y la promoción de la equidad en el gasto, la dismi- 
nución en los niveles de evasión y de "elusión" tributaria, la simplificación de la estructura tributaria y la transparencia en la inversión y el gasto público. La política de "Reforma del sistema financiero" iría encaminada a poner al sistema financiero "al servicio del desarrollo del país y... [articularlo] a los otros sectores de la economía", mediante políticas de oferta de fondos para fines productivos; la implementación de regulaciones que fomenten la competitividad, transparencia y confianza del sistema financiero; el fortalecimiento de la autonomía de los entes supervisores; y el fomento de la capacidad de control de la sociedad civil.

Las políticas de "Desarrollo rural" perseguirían "diversificar la estructura productiva y mejorar las formas de organización de la producción, en busca de mejores condiciones de vida" a través de medidas que, a corto plazo, procurarían mejorar los precios al productor agropecuario, reducir los costos de producción, incrementar la disponibilidad de crédito y la creación de un fondo de emergencia. La mayor parte de estas medidas contemplan la creación
Las grandes áreas de acción que [el FMLN-USC] se proponen son: "Más y mejor empleo", "Política fiscal”, "Reforma del sistema financiero", "Desarrollo rural", "Política industrial", "Micro, pequeña y mediana empresa", "Formación de ahorro interno", "Asignación y regulación de las inversiones", "Protección al consumidor" y, finalmente, el "Desarrollo local". cro y pequeña empresa industrial y la integración al mercado regional. Finalmente, las políticas dirigidas a la "micro, pequeña y mediana empresa" buscarían -al igual que las dirigidas a la industria - incrementar su productividad y articulación con el resto del sistema productivo nacional. Para ello, se procuraría la generación de condiciones que faciliten el acceso de este sector al crédito, adecuación del marco legal para la inclusión de estas empresas, capacitación y asistencia técnica, innovación tecnológica y mercadeo, así como el fomento de la gremialización.

\section{Políticas sociales}

Es a todas luces evidente que uno de los puntos más débiles de la institucionalización democrática en El Salvador tiene que ver con el desarrollo social. Si bien es innegable que pasos importantes se han dado en el fortalecimiento de la democracia política, también lo es que demasiado poco se ha hecho para avanzar en la consolidación de la democracia social. En los últimos años, la erradicación de la pobreza se ha convertido en un lugar de barreras arancelarias a productos que compitan con la producción nacional, así como la creación de subsidios y fondos especiales de crédito. En el mediano plazo, el desarrollo rural se buscaría a través de una política social descentralizada, una política de medio ambiente y la implementación de políticas a nivel macro y sectorial para el desarrollo rural. Estas medidas contemplan los mismos instrumentos fiscales que las de corto plazo, pero añaden la modernización del Ministerio de Agricultura y Ganadería (MAG) y el fomento de la transferencia tecnológica a los productores rurales.

La política industrial persigue, fundamentalmente, incrementar la competitividad de la industria y articularla con el resto de sectores económicos a través de políticas de armonización de las áreas macroeconómica y fiscal, la creación de un nuevo rol de apoyo del sector público, el impulso de la investigación científica, el fomento de la mi- común en los discursos de los políticos. No obstante, ni el partido oficial ni los partidos de oposición han sabido dar respuesta a las necesidades básicas que la población demanda. Dado que las políticas sociales son uno de los aspectos determinantes a la hora de hablar de superación de la pobreza, exponemos a continuación las propuestas que los dos partidos políticos mayoritarios hicieron en este nivel.

\subsection{ARENA: "Alianza solidaria"}

Es en la tercera parte de su plataforma de gobierno donde Francisco Flores expone las políticas sociales que impulsará desde la presidencia de la república para promover el desarrollo social. Así, en la "Alianza solidaria", las tres principales áreas de compromiso son: (1) participación social y descentralización; (2) generación de oportunidades para progresar, y (3) acceso a servicios sociales 
básicos. Aunque en el punto (1) se plantean como objetivos la "consolidación de la democracia" y el "éxito de la descentralización", la "participación social y la descentralización" se entienden más bien como un paulatino traspaso de la propiedad y administración de algunos de los servicios básicos del Estado hacia el sector privado.

Con ello, según el documento, se garantizarían "servicios de mayor calidad" y más accesibles a la ciudadanía. Teniendo en cuenta estos objetivos, las acciones que se ejecutarían son: $(a)$ establecer mecanismos de comunicación y coordinación del gobierno central con los gobiernos locales para garantizar una efectiva ejecución de la inversión pública; $(b)$ asegurar recursos financieros del gobierno central para transferir a las municipalidades, para el desarrollo de proyectos de infraestructura de servicios y productivos de competencia municipal; (c) promover la participación social en la prestación de servicios básicos por medio de modalidades contractuales de gestión; y $(d)$ institucionalizar mecanismos de supervisión y auditoría social en la provisión de servicios públicos.

En el punto (2), "generación de oportunidades para progresar", se plantean las políticas encaminadas a robustecer el sistema de educación nacional, partiendo del supuesto de que "a mayores niveles educativos mayor es el bienestar y las oportunidades de desarrollo". Los objetivos de esta área de compromiso son: (a) elevar la cobertura, calidad y pertinencia de la educación parvularia, básica, media y superior; (b) aumentar la eficiencia, eficacia y equidad del sistema educativo; $(c)$ hacer de la educación un medio efectivo para formar en los niños y jóvenes la conciencia de valores; y (d) vincular el proceso educativo al desarrollo de la tecnología y la productividad.

Fundamentalmente, esta área se orienta a la "profundización de la Reforma Educativa" por medio de: (a) la ampliación de la cobertura de la educación a partir del tercer ciclo en áreas rurales y suburbanas, el establecimiento de fondos de becas para estudiantes destacados y la rehabilitación de la infraestructura escolar básica y media; $(b)$ el mejoramiento de la calidad educativa, lo que implica introducir herramientas tecnológicas (computadoras, internet, televisión, vídeo), la enseñanza

del idioma inglés, nuevos estándares curriculares y apuntalar los sistemas de evaluación y supervisión de la educación, entre otros; (c) el establecimiento de un sistema de incentivos a la excelencia docente y la promoción de la capacitación de los maestros; y (d) la descentralización de la educación a través de la participación del sector privado en la administración de los institutos tecnológicos, la reorientación del financiamiento educativo y su administración, y una mayor autonomía de los Consejos Directivos Escolares.

Entendiendo que los servicios sociales básicos "son el soporte material para los esfuerzos productivos de las comunidades y para mejorar la calidad de vida de los ciudadanos", el tercer apartado de la "Alianza solidaria" ("acceso a servicios sociales básicos") se plantea como objetivo general: "mejorar la calidad de vida de las comunidades y las familias", y más específicamente: (a) facilitar el acceso de la población a una vivienda digna; $(b)$ asegurar un suministro continuo de agua a precios competitivos; $(c)$ aumentar la calidad y cobertura de los servicios públicos de salud, priorizando los programas preventivos, de saneamiento básico y de promoción de la salud; y $(d)$ contar con un Ministerio de Salud Pública y Asistencia Social (MSPAS) fortalecido para ejercer su función de regulación y vigilancia de la calidad de los servicios de salud.

Las acciones por ejecutar para dar cumplimiento a estos objetivos se agrupan en tres campos: acceso a vivienda, modernización del subsector agua y saneamiento, y reforma del sector salud. Las políticas relacionadas con el acceso a la vivienda son: (a) garantizar la agilización del pro- 
ceso de titulación de tierras, impulsar la promulgación de la ley de ordenamiento territorial y, en coordinación con los sectores pertinentes, una Política Nacional de Vivienda; (b) facilitar los mecanismos para el financiamiento de viviendas y aumentar los recursos estatales orientados a la vivienda popular; y $(c)$ fortalecer la participación municipal y comunitaria para facilitar el acceso a servicios básicos en los programas de FONAVIPO.

En relación al segundo campo, las políticas más importantes son: (a) la reasignación institucional de los roles de rectoría y concesión de derechos de agua, regulación, supervisión y operación de sistemas; (b) el impulso de la promulgación de la Ley de Aguas y la creación de un ente rector que coordine la política hídrica y administre la asignación y concesión de derechos de uso de agua; (c) la descentralización de la producción y distribución del sistema de agua potable de ANDA, mediante contratos de administración o concesión; y $(d)$ la liberalización de la producción de agua potable para propiciar la participación privada y mejorar el acceso a este recurso.

Finalmente, las políticas relacionadas con la reforma del sector salud son: (a) promover el establecimiento del Consejo Asesor de Salud para fortalecer la coordinación y propiciar la reforma del sector; (b) reorganizar y modemizar las funciones del MSPAS; (c) aplicar estrategias para la organización, financiamiento y prestación de servicios de salud en forma descentralizada y con participación de las organizaciones no lucrativas, comunitarias y empresas privadas; $(d)$ promover la aprobación del nuevo Código de Salud y fortalecer las instancias del MSPAS responsables de su aplicación; (e) crear el sistema de información de salud pública; y $(f)$ modemizar y fortalecer la capacidad de monitoreo y vigilancia del MSPAS sobre los establecimientos y servicios de salud públicos y privados.

\subsection{FMLN-USC: "Invertir en la gente"}

Invertir en la gente es el primer apartado de la plataforma gubernamental de la coalición FMLNUSC. En él se desarrollan las distintas políticas que dicha coalición plantea en materia social. Tales políticas están encaminadas a las áreas de: educación, salud, sistema previsional, vivienda, niñez y adolescencia, deporte, servicios públicos esenciales y transporte. Por razones de espacio, sólo detallaremos aquí los que consideramos más relevantes.
El plan de gobiemo del FMLN-USC reconoce los esfuerzos realizados hasta ahora en materia educativa. Señala, sin embargo, que esa rama continúa siendo deficitaria en términos de infraestructura, formación docente y recursos didácticos básicos. Con el fin de responder a esta problemática, la plataforma en cuestión establece los objetivos siguientes: (a) ampliar la cobertura de la educación tanto en áreas rurales como urbanas; $(b)$ incrementar el desarrollo de la calidad de la educación nacional potenciando el desarrollo científicotécnico; $(c)$ crear una visión de nación salvadoreña en los educandos que fortalezca la práctica de valores apropiados para una nueva sociedad; y $(d)$ fortalecer la identidad cultural nacional mediante el fomento de los valores culturales y artísticos.

Para lograr tales objetivos, las estrate $z$; y medidas por seguir serían: (a) retomar la investigación pedagógica y la formación de maestros mediante Escuelas Normales Regionales; $(b)$ propiciar la participación de organismos gubernamentales y no gubernamentales y comunidades en el diseño y administración de las políticas educativas; (c) garantizar la gratuidad en la educación básica; (d) facilitar el acceso de un número mayor de mujeres a la educación; (e) promover sistemas de becas y créditos que posibiliten la formación media y superior/de estudiantes de escasos recursos; $(f)$ potenciar la formación técnica formal y no formal con el fin de mejorar la inserción laboral de acuerdo con las necesidades productivas; $(g)$ incorporar en los planes curriculares ejes transversales, tales como Derechos Humanos, equidad de género, Medio Ambiente y cultura de paz; $(h)$ impulsar, en coordinación con las instituciones que fomentan los valores culturales y artísticos, programas que promuevan el rescate de la identidad nacional; $(i)$ crear un fondo nacional para la promoción y divulgación de la cultura y el patrimonio histórico; y (j) promover las artes en la educación superior.

En materia de salud, el plan de gobierno del FMLN-USC señala que importantes sectores de la población carecen de atención, hay una débil promoción de la salud y prevención a la enfermedad $y$, además, el sistema de salud se encuentra fragmentado y sin liderazgo por parte del Ministerio de Salud Pública y Asistencia Social (MSPAS). Por esa razón, se considera urgente desarrollar una "profunda reforma" del sector salud, propiciando una participación amplia para configurar un "Pac- 
to Social por la Salud". El objetivo a lograr sería: "elevar el nivel de salud de la población a través de": (a) la construcción de un sistema nacional de salud integral rectorizado por el MSPAS, que sea equitativo, accesible, eficiente, participativo y solidario; y $(b)$ la integración de las acciones de salud con el resto de sectores que están directamente involucrados con el desarrollo de las necesidades humanas fundamentales.

Para la concreción de dicho objetivo se proponen estrategias y medidas como: $(a)$ readecuar el financiamiento a las necesidades de salud de la población; $(b)$ enfatizar en la prevención, la promoción y la calidad; $(c)$ descentralizar eficientemente; $(d)$ apoyar la investigación en salud; $(e)$ fortalecer los mecanismos de información y supervisión del sistema; $(f)$ concertar permanentemente con el sector privado; $(g)$ reformar el seguro social permitiendo la ampliación de la cobertura y la desburocratización; $(h)$ crear un Consejo Nacional de Salud; $(i)$ formular una política de incentivos económicos y cualificación del personal en todos los niveles del sistema; $(j)$ desarrollar la investigación de prácticas de salud comunitarias y alternativas a las tradicionales; $(k)$ regular con estándares de calidad los servicios de salud, práctica médica y suministro de medicamentos; y $(l)$ dar prioridad a programas relacionados con prevención y asistencia de enfermedades producto de la violencia, salud ocupacional, salud integral de la mujer y la niñez, salud mental, rehabilitación, política de medicamentos (calidad, uso racional, accesibilidad) y salud-Medio Ambiente.

En cuanto a la política habitacional, la plataforma del principal partido de oposición cuestiona la ausencia de un sistema nacional de planificación territorial y de facilidades en la adquisición de vivienda. Dado tal diagnóstico, se formula el siguiente objetivo: superar el déficit habitacional que vive el país en el ámbito rural y urbano, así como avanzar en el establecimiento de un sistema de planificación territorial que reglamente el uso del suelo en beneficio del hábitat. Para alcanzarlo se propone: $(a)$ reestructurar la institucionalidad del Estado vinculada al hábitat (Viceministerio de Vivienda, FONAFIPO, etc.), en concordancia con las exigencias actuales de vivienda; $(b)$ descentralizar los programas de vivien- da de manera que sean los municipios y la población parte activa en la ejecución de los proyectos, de modo que se garantice vivienda digna en las zonas rurales; $(c)$ crear o fortalecer el ente rector estatal responsable del diseño y supervisión de la política habitacional y de subsidios a los sectores económico sociales más desprotegidos; $(d)$ favorecer la participación privada en la política habitacional; $(e)$ promover líneas de crédito a largo plazo con tazas de interés accesibles que permitan a las familias más pobres adquirir vivienda, remodelarla o construirla; $(f)$ impulsar la planificación del crecimiento urbano, asegurando un mejor ordenamiento territorial; $(g)$ impulsar modelos de vivienda en armonía con la naturaleza; y $(h)$ desarrollar una política de control de costos del alquiler de vivienda.

No se puede dejar de señalar, aunque brevemente, la propuesta de la izquierda en materia de servicios básicos y previsión social. Con respecto al primero, la coalición FMLN-USC se propone como objetivo: "garantizar mayor cobertura, calidad y transparencia en la prestación de los servicios básicos esenciales". Para lo cual propone: $(a)$ establecer deberes y derechos del usuario, así como facultades y obligaciones de los prestadores de servicios públicos y privados; $(b)$ fortalecer la capacidad de arbitraje de la SIGET y crear entes reguladores de los demás servicios; $(c)$ incrementar la eficiencia en la generación de energía e impulsar un proceso de descentralización progresiva del servicio de agua; y $(d)$ fortalecer el fondo de la FINET con el fin de asegurar la ampliación de cobertura y el subsidio de las tarifas a sectores de bajos ingresos.

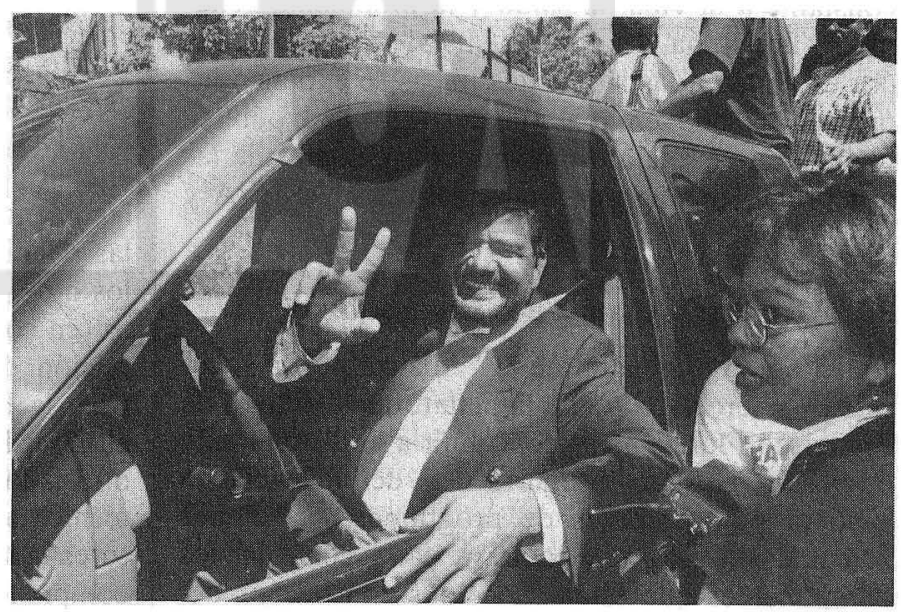


En relación con el sistema de pensiones, el plan de gobierno en cuestión busca readecuarlo "hacia un régimen mixto complementario que asegure una vejez digna para la población". Para este fin se propone: $(a)$ rescatar el rol constitucional de Estado en el régimen previsional, incorporando la participación de las AFPs de manera complementaria a las prestaciones del sistema público; $(b)$ extender la cobertura hacia los sectores sociales desprotegidos; (c) hacer un estudio técnico del costo fiscal de la actual reforma, insostenible a juicio de la coalición; $(d)$ reformar la ley actual de pensiones con el fin de proteger los derechos laborales y respetar el derecho constitucional de libre elección en la afiliación; y (e) reorganizar la Superintendencia de Pensiones para garantizar su transparencia e imparcialidad.

\section{Seguridad Pública}

Evidentemente, el gobierno de Armando Calderón Sol ha sido incapaz de dar una respuesta eficaz al problema de la seguridad pública. No sólo la delincuencia común y el crimen organizado continúan aumentando sin que la labor de la Policía Nacional Civil pueda dar muestras de un mejor rendimiento, sino que, además, la corrupción y la impunidad continúan estando a la orden del día, sin que las instituciones pertinentes hayan podido articularse en torno a una estrategia definida de garantía irrestricta al cumplimiento de la legalidad. Diversas encuestas de opinión pública han evidenciado que es la inseguridad ciudadana el problema que más aflige a la población salvadoreña. Y no es para menos. La delincuencia común y el crimen organizado constituyen una amenaza constante a la vida, la salud y la propiedad, generando un clima de permanente desconfianza. Es por eso que en las siguientes líneas se exponen las propuestas que en materia de seguridad pública plantearon las plataformas gubernamentales de las dos principales agrupaciones políticas: ARENA y FMLN-USC

\subsection{ARENA: “Alianza por la seguridad"}

El objetivo general de la "Alianza por la seguridad" - tercera parte de la plataforma electoral de Francisco Flores- es "contribuir a la disminución de los niveles de inseguridad y delincuencia en todo el país a través de programas y acciones orientadas a prevenir, contrarrestar y controlar los componentes que están asociados con hechos de- lictivos y con la violencia". De manera resumida, sus objetivos específicos son los siguientes: $(a)$ conocer la violencia y sus causas para diseñar políticas de acción concretas; $(b)$ brindar apoyo a la Policía Nacional Civil y a las instituciones judiciales en el desarrollo de políticas nacionales de seguridad; $(c)$ facilitar la convivencia social y controlar la violencia ciudadana; $(d)$ controlar la violencia y la delincuencia a nivel local; $(e)$ propiciar el intercambio -nacional e internacional- de experiencias exitosas entre ciudades e instituciones; y $(f)$ fortalecer el cuerpo de leyes de manera que se permita el castigo ejemplarizante al delincuente y se disuadan las actitudes delictivas potenciales.

Con estos objetivos, la "Alianza por la seguridad" establece sus estrategias de acción atendiendo a cuatro áreas: (1) seguridad pública; (2) seguridad y defensa nacional; (3) seguridad jurídica; y (4) seguridad a la población en caso de desastres. A su vez, la primera de estas se divide en: $(a)$ el fortalecimiento de la capacidad de aplicación de la ley; $(b)$ reformas legales e institucionales; $(c)$ readaptación del delincuente; y $(d)$ el fortalecimiento de la cultura de la paz.

Según la plataforma, el fortalecimiento de la capacidad de la aplicación de la ley pasaría por un fortalecimiento de la Policía Nacional Civil y el establecimiento de sistemas de investigación, asistencia técnica e información. Con respecto a la PNC se propone, entre otras cosas: (a) llevar a cabo una reforma institucional del cuerpo a través del establecimiento de una reglamentación para los ascensos, la profesionalización de sus integrantes y el fortalecimiento de las instancias responsables de su control, depuración y evaluación; (b) establecer nuevas estrategias de acción, tales como el perfeccionamiento de las capacidades investigativas y de inteligencia policial, la sustitución de los Grupos de Tarea Conjunta por la Policía Nacional Civil rural, y el control estricto de las armas en poder civil y de las agencias privadas de seguridad; y (c) mejorar las relaciones de la PNC con la comunidad y con los otros entes involucrados en la seguridad pública (en concreto, se propone la creación de una Comisión de Enlace integrada, entre otros, por la CSJ, la FGR, el Ministerio de Seguridad Pública, el CNJ, la PDDH y la Asamblea Legislativa). Por otro lado, los sistemas de investigación, asistencia técnica e información buscarían integrar a los sectores académicos/científicos en el esfuerzo de comprender las causas y efectos de la violencia y 
el delito. Los resultados de esta participación técnica pasarían a ser discutidos por la ciudadanía y las organizaciones sociales pertinentes, a fin de articular y evaluar los esfuerzos contra la violencia.

En lo que se refiere al punto $(b)$ del área de seguridad pública, las reformas legales por implementar son: una Política Criminal Integral con énfasis en la prevención del delito; reformas legales para el combate del narcotráfico, el contrabando y la defraudación financiera; armonizar la legislación penal y procesal penal con el resto de la normativa legal; fortalecer el Consejo Nacional de la Seguridad Pública e impulsar la legislación relativa al crimen organizado, el tráfico de menores e ilegales, y la extradición. Complementariamente, las iniciativas institucionales estarían enfocadas a fomentar la colaboración entre los entes del Estado, diseñando para ello mecanismos de resolución de conflictos y programas de conciliación institucional.

Para la readaptación del delincuente se plantea, por un lado, la modemización de la administración penitenciaria, lo que significaría controlar las actividades delictivas en el interior de los penales, fomentar proyectos ocupacionales y educativos para los reclusos, diseñar políticas de readaptación y reinserción social, y apoyar los esfuerzos enfocados a la agilización de los procesos judiciales. Por el otro, diseñar políticas especiales -involucrando a la ciudadanía - para la reclusión, readaptación y reinserción de jóvenes infractores. Adicionalmente, se esbozan políticas para prevenir el delito (brindar ofertas de empleo, estudio y capacitación, por ejemplo), aunque ellas sólo están dirigidas a "menores en riesgo social o con comportamiento antisocial". Sobre el fortalecimiento de la cultura de paz, la "Alianza por la seguridad" propone, fundamentalmente, el diseño de una estrategia que, a través de la educación y los medios de comunicación, insufle en la ciudadanía una escala de valores asociados a la conciliación, la convivencia pacífica y el respeto de la ley.

En la segunda área de la "Alianza por la seguridad" (Seguridad y Defensa Nacional), no hay mucho que reseñar, pues sus planteamientos son escasos y no aportan nada nuevo al papel asignado a la Fuerza Armada luego de la firma de los acuerdos de paz. En la tercera área, seguridad jurídica, las políticas planteadas están dirigidas a seis campos: ( $a$ ) administración pública en general, en la cual se buscaría combatir la corrupción por medio del fortalecimiento de los mecanismos legales e institucionales destinados a regular y controlar la acción de los funcionarios gubernamentales; $(b)$ propiedad, principalmente enfocándose en el robustecimiento de los mecanismos para establecer la propiedad de la tierra y la aplicación de la Ley de Propiedad Intelectual; $(c)$ publicación y difusión de la ley, entendida en el documento como actualización y armonización de la legislación; $(d)$ activa colaboración de la ciudadanía en la revisión y promulgación de nuevas leyes por parte de la Asamblea Legislativa; (e) administración de justicia (apoyar la autonomía del Consejo Nacional de la Judicatura, colaborar con la Corte Suprema de Justicia en la aplicación de la ley, y crear mecanismos de apoyo para la operación y administración de la justicia); y $(f)$ fiscalizar el ejercicio de los abogados y elevar el nivel de educación de la carrera de leyes.

Finalmente, en la cuarta área, seguridad en casos de desastres, se pretende, en primer lugar, identificar las áreas de riesgo con el fin de elaborar políticas de prevención de desastres y de reconstrucción de áreas afectadas; en segundo lugar, fortalecer y actualizar a las organizaciones que estudian e identifican las zonas de riesgo, y aquellas que atienden los desastres; en tercer lugar, establecer una normativa que establezca las formulas de acción y los medios de cooperación ante situaciones de desastre.

\subsection{FMLN-USC: "Un país seguro"}

El Plan de Gobierno de la coalición FMLNUSC se preocupa en señalar el déficit que actualmente existe en materia de seguridad pública y "la falta de voluntad política para brindar seguridad al pueblo salvadoreño". Al respecto, sostiene: "al interior de las instituciones de seguridad pública se han evidenciado debilidades, vacíos, distorsiones; unos producto del desarrollo y otros provocados 
por funcionarios que persistentemente han tratado de distorsionar el carácter civil, democrático, y de respeto a los Derechos Humanos de la PNC. En todo caso la PNC no ha respondido a las expectativas de la población lo que se expresa en aumento del personal de las empresas privadas, contratación de vigilancia privada y mayor número de solicitudes de portación de armas por particulares".

De acuerdo con la plataforma en cuestión, el problema de la seguridad es "fundamental". Se proponen allí medidas encaminadas a combatir la delincuencia, la corrupción y la impunidad y a volver eficiente la administración de justicia. En materia delincuencial, las estrategias a seguir por parte del “Gobiemo de concertación" serían: (a) "mejorar sensiblemente los mecanismos institucionales orientados a la vigilancia, persecución, juicio y rehabilitación de los delincuentes"; y $(b)$ incrementar sensiblemente la inversión social y la generación de empleo".

La concreción de esas estrategias pasaría por: (a) dar prioridad a la protección de los derechos de las personas, sin desmedro de la seguridad a la propiedad privada y al patrimonio público; (b) combatir la impunidad y procurar el fiel cumplimiento de las leyes; $(c)$ establecer una política preventiva del delito; (d) diseñar un plan de seguridad pública que fortalezca a las instituciones pertinentes y procure la integración de sus esfuerzos; $(e)$ promover la participación ciudadana en la prevención e investigación del delito y propiciar una relación cordial entre la policía y la comunidad; $(f)$ designar en la dirección de los organismos de seguridad pública a un equipo de personas altamente capacitadas y con voluntad férrea de combatir a fondo la delincuencia y el crimen organizado; $(g)$ crear un sistema nacional de inteligencia, información y estadística criminal para el apoyo a la Fiscalía, al Órgano Judicial y a la Policía Nacional Civil; $(h)$ promover una apropiada asignación presupuestaria a las entidades encargadas de la seguridad pública; ( $i$ ) apoyar las reformas al marco jurídico del sistema de seguridad pública para volverlo oportuno y eficiente; $(j)$ la pronta aplicación de las leyes del sistema penitenciario, con el fin de mejorar las condiciones de los centros penales y llevar a cabo programas de rehabilitación y capacitación; y $(k)$ garantizar estabilidad laboral, una política salarial justa y reconocimiento social a todo el personal de seguridad pública, depurando a aquellos elementos que no llenen los requisitos morales y profesionales.
Por otra parte, cabe mencionar que la plataforma en cuestión dedica un apartado al planteamiento del problema de la corrupción y a las propuestas dirigidas a enfrentarlo. Ahora, si bien es cierto que tal problema compete a otras áreas - como la modernización del estado, por ejemplo-, también lo es que la corrupción no debe dejar de considerarse como un aspecto de suma importancia cuando de seguridad pública se trata. De ahí su inclusión en este recuento.

Sostiene la coalición en su plan de gobierno que "la corrupción es uno de los factores que contribuyen a agudizar los problemas del subdesartollo y a malograr los empeños orientados al desarrollo económico social". Señala, además, que "el abuso de poder, el tráfico de influencias, las licitaciones amañadas que encarecen exorbitantemente las obras y servicios y minimizan la calidad de los mismos..., el soborno, el despilfarro de recursos, la evasión tributaria, el nepotismo, el clientelismo, la compra y venta de políticos, son algunas de las usuales formas de corrupción en El Salvador de hoy".

Para dar respuesta a tan grave situación, la plataforma asegura que el "Gobierno de Concertación estará fundado en la Ética del Servicio como eje motivacional de la nueva gestión gubernamental". "EL nuevo Gobierno - reitera- declarará una lucha permanente, integral y sin tregua a la corrupción. Por eso mismo tendrá una estrategia dirigida a prevenir, detectar, sancionar y erradicar las prácticas corruptas".

La concreción de dicha estrategia pasaría por: (a) desarrollar programas de promoción de derechos y deberes ciudadanos, educación cívica y valores éticos entre la sociedad; (b) promover una "Cultura de la Honradez" entre empleados y funcionarios, incentivando la participación ciudadana, a fin de desarrollar una masa crítica que ayude a mejorar los niveles de producción y calidad de los servicios de las instituciones públicas; $(c)$ desarrollar un alto nivel de transparencia en la gestión gubernamental, proveyendo información pública sobre el manejo de los recursos del Estado; (d) fortalecer la independencia de los organismos de control y de su competencia profesional, de tal modo que la credibilidad en ellos pueda elevarse; (e) procurar que la corrupción sea declarada un delito de lesa humanidad y un acto de violación a los Derechos Humanos por los organismos regionales e internacionales; $(f)$ crear un Código de Ética Gubernamental para todos los funcionarios y 
empleados públicos; $(g)$ fundar la Oficina de Ética Gubernamental y una instancia independiente y accesible para la recepción de denuncias relacionadas con el manejo de los recursos del Estado; $(h)$ promover la Ley de Acceso Público a la información pública; $(i)$ elaborar una Ley de Contratación de Bienes y Servicios que asegure la publicidad, equidad y eficiencia de los mismos; y $(j)$ desarrollar sistemas de contratación de funcionarios y empleados públicos basados en los principios de capacidad y honradez.

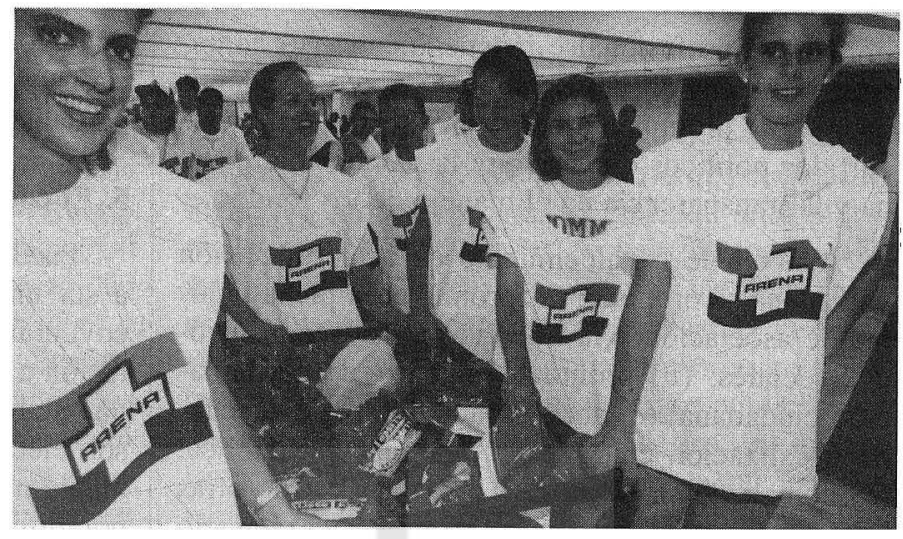

\section{Democratización y participación ciudadana}

Si algo lograron los acuerdos de paz, firmados en 1992, fue sentar las bases para la construcción de una sociedad democrática. De hecho, desde entonces hasta ahora, los mayores avances en el desarrollo del país se han dado en materia política. No cabe duda de que la libertad de expresión, la independencia de poderes, la relativa pluralidad de partidos y la mayor transparencia en los procesos electorales son pasos importantes en la institucionalización democrática. Empero, la diversidad de prácticas comuptas que continúan predominando en las instancias gubernamentales y la incapacidad de los funcionarios públicos de dar respuestas concretas a los problemas nacionales, también son realidades; realidades que ponen serios obstáculos al proceso de democratización del país. Es por eso conveniente evaluar las propuestas que en este aspecto plantean las principales fuerzas políticas de El Salvador. En eso consistirán las líneas siguientes.

\subsection{ARENA: "Participación local y descentrali- zación"}

En la "Alianza Solidaria" de la plataforma de ARENA, es el apartado "participación local y descentralización" el que compete a este resumen. En él se señalan los objetivos específicos siguientes: "avanzar en el proceso de consolidación de la democracia", "fortalecer las instancias locales en las que se delegan funciones para garantizar el éxito de la descentralización", "que los usuarios se beneficien con servicios de mayor calidad" y "acercar los servicios a la ciudadanía".

Para concretar tales objetivos se propone: $(a)$ establecer mecanismos de coordinación entre el gobierno central y los gobiernos locales para garantizar una efectiva ejecución de la inversión pública; $(b)$ transferir recursos del gobierno central a las municipalidades, para el desarrollo de proyectos de infraestructura de servicios sociales; $(c)$ promover la participación social y la corresponsabilidad en la prestación de servicios básicos, tales como caminos, telefonía, electrificación rural, agua, saneamiento, salud, cultura, recreación y deportes; $(d)$ institucionalizar mecanismos de supervisión y auditoría social en la provisión de servicios públicos; y $(e)$ crear mecanismos para fortalecer vínculos de salvadoreños en el exterior con sus comunidades de origen.

\subsection{FMLN-USC: "Más democracia y mayor participación ciudadana"}

Este es el nombre del capítulo uno del "área política" de la plataforma del FMLN-USC. Se plantean allí políticas para la modernización del sistema político, el fortalecimiento de la participación ciudadana, la efectiva competencia e independencia de los poderes públicos y el acceso ciudadano a la información. Sumado a esto, cabe señalar la "política para la descentralización del Estado", contemplada en el capítulo 2 de esa misma área.

En cuanto a la modernización del sistema político, las propuestas son: (a) implementar una reforma al sistema de representación política para alcanzar un efectivo ejercicio del sufragio; $(b)$ democratizar el sistema electoral y hacerlo creíble y confiable; $(c)$ institucionalizar el Voto Residencial; (d) implementar un sistema de participación proporcional en los Consejos Municipales; (e) legitimar la aceptación de candidaturas no adscritas a partidos políticos en el ámbito municipal; $(f)$ transformar el Tribunal Supremo Electoral en un 
organismo profesional e independiente; $(g)$ garantizar la obtención del documento único de identidad; y $(h)$ promover la aprobación de una ley de partidos políticos que asegure la democracia interna y la transparencia en el manejo de los fondos.

A nivel de fortalecimiento de la participación ciudadana se propone: $(a)$ promover la plena libertad de asociación y la libertad de las organizaciones sociales; $(b)$ promover una ley de participación ciudadana; (c) abrir espacio para una adecuada fiscalización ciudadana de la cuestión pública; (d) actualización de la Ley de ONG's y de otras iniciativas ciudadanas; y $(e)$ promover el ejercicio de la democracia directa y semidirecta por medio del referéndum, el plebiscito y la iniciativa popular. En materia de competencia e independencia de poderes, las medidas a tomar serían: (a) impulsar un combate frontal y permanente contra la corrupción y erradicar el clientelismo y la impunidad; $(b)$ implementar un proyecto dirigido a viabilizar la reforma judicial pactada en los acuerdos de paz; y (c) fortalecer la independencia de los organismos de Contraloría Estatal.

Para favorecer el acceso de la ciudadanía a la información se propone: $(a)$ asegurar la apertura a la información y la libre competencia de los medios de comunicación; (b) garantizar el derecho de respuesta como componente fundamental del respeto a los derechos humanos en los medios de comunicación; $(c)$ respetar las garantías y los derechos de los profesionales de la comunicación; $(d)$ el estado de las Finanzas Públicas se divulgará periódicamente sobre la base de un calendario de publicaciones; y (e) los anteproyectos de ley más importantes serán publicados para que la ciudadanía opine previamente a su aprobación.

Finalmente, en lo que respecta a la descentralización del Estado, el plan de gobiemo en cuestión propone: $(a)$ otorgar a cada territorio mayor capacidad de gestión y posibilidades de viabilizar un proceso de desarrollo equitativo y sustentable; $(b)$ promover la Ley Especial de Descentralización y la Ley de Ordenamiento Territorial, entre otras; (c) implementar la transformación del gobierno central y redefinir todo el aparato ministerial; $(d)$ proponer las modificaciones necesarias para los otros poderes del Estado; (e) rediseñar el sistema de ingresos y transferencias de los municipios y crear el impuesto predial; además, crear un sistema nacional de crédito y fondos de contrapartida para el fomento municipal y regional; y $(f)$ crear una instancia nacional, plural y representativa, que sea la responsable de orientar y conducir el proceso.

\section{El componente de género}

Puede asegurarse que el sector femenino pasó a ser un componente bastante significativo en la coyuntura electoral. De forma simbólica, esta apelación a las mujeres puso de manifiesto el espacio que se les está abriendo en el marco de los procesos electorales. Es decir, lo que antes era totalmente negado a las mujeres es, en la actualidad y por diferentes motivos, altamente fomentado. La promoción del derecho al sufragio ya no se limita a una invitación general. Los directores de campaña y los políticos en contienda se dirigen al sector femenino como un grupo particular de la sociedad. Por constituir las mujeres una significativa cantidad de votantes y probables seguidoras, algunas de las ofertas electorales son dirigidas a ellas especialmente, pues, aunque todos los problemas del país les conciernen tanto a hombres como a mujeres, estas últimas tienen problemas específicos $\mathrm{y}$, por ende, necesitan un gobierno dispuesto a resolvérselos o, al menos, a prestarles la atención debida. Por conveniencia o verdadera convicción, dichas políticas fueron plasmadas en los planes de gobierno de los partidos políticos mayoritarios. Aun con la desconfianza debida, es de celebrar la existencia de la visión de género dentro de ambas plataformas, pues ello significa un avance. En las líneas siguientes se describirán, a grandes rasgos, lo que tales plataformas propusieron a las mujeres.

\subsection{ARENA: "Apoyo a la mujer jefa de hogar"}

En el Programa de Gobierno de ARENA se advierte, desde un principio, la ausencia de aspectos referentes a la mujer en los temas más generales. No es sino hasta el capítulo II, denominado "Alianza Solidaria", en el que se vislumbran algunos objetivos gubernamentales dedicados al tema de género. Este capitulo tiene 4 áreas de compromiso, una de las cuales es el "Desarrollo personal e integración familiar". Dentro de éste se propone: "redefinir el rol del Estado en la atención a la mujer"; "aumentar y promover la transparencia de recursos a entidades y organizaciones que atienden a grupos vulnerables" y "descentralizar la atención de la mujer". Se menciona, además, que uno de los objetivos de esta área es "crear condiciones que faciliten el desarrollo y bienestar de la mujer". 
El apartado específicamente dedicado a la problemática femenina se denomina "Apoyo a la Mujer Jefa de Hogar". Las propuestas allí planteadas son: (a) modernizar y fortalecer la Procuraduría General de la República ampliando la cobertura y efectividad de los programas de asistencia legal contra la violencia intrafamiliar y la paternidad irresponsable; $(b)$ fortalecer la capacidad rectora y normativa de la Secretaría Nacional de la Familia (SNF) y la capacidad de gestión del Instituto para el Desarrollo de la Mujer (ISDEMU); (c) fortalecer la coordinación interinstitucional de los organismos involucrados en la protección de la mujer, la niñez y la familia; $(d)$ fortalecer los sistemas de estadística e información de los casos de violencia intrafamiliar $y$ apoyar los programas de rehabilitación de salud mental de las víctimas; $(e)$ fortalecer y buscar mecanismos que permitan ampliar los programas "Escuela Saludable" y "Guarderías Infantiles", para facilitar el cuido de los niños, apoyar su alimentación y brindarles estimulación temprana; y $(f)$ dar prioridad a los hijos de mujeres jefas de hogar, que cumplan con los requisitos, en el otorgamiento de becas de estudio.

\subsection{FMLN-USC: "Política de promoción de la mujer"}

Así se denomina el apartado en el que el FMLNUSC toca específicamente la temática del sector femenino. Al respecto señala que "en este sector prevalecen altos niveles de analfabetismo, desprotección en las prestaciones sociales, grandes deficiencias en el acceso a la propiedad y al crédito. La participación política de las mujeres en El Salvador debe potenciarse para que puedan ser representadas en las instancias formales como la Asamblea Legislativa, Alcaldías, Consejos Municipales y Ministerios". Para lograr dicha potenciación, la coalición, entre otras cosas, propone: $(a)$ fortalecer el ISDEMU como organismo rector de la política nacional de la mujer a fin de incorporar la perspectiva de igualdad de géneros en toda la gestión gubernamental; (b) promover la adecuación de la legisla- ción nacional a las convenciones internacionales de las Naciones Unidas y de la OEA, a favor de las mujeres; (c) "igual salario por igual trabajo"; $(d)$ garantizar el acceso al crédito, a la tierra y a la tecnología; (e) impulsar programas de salud integral a la mujer, atención gratuita o de bajo costo en salud reproductiva y sexual; $(f)$ promover medidas jurídicas, políticas y sociales para erradicar la violencia en contra de las mujeres; $(g)$ promover las cuotas de participación de las mujeres en cargos públicos y en los organismos de dirección partidarios; $(h)$ mejorar las capacidades de la Procuraduría General de la República para hacer efectiva la responsabilidad paterna; e (i) combatir, sancionar y erradicar toda forma de abuso y maltrato infantil en las niñas.

\section{Consideraciones}

En materia económica, los dos programas partidarios tienen múltiples puntos coincidentes, tales como la importancia de la generación de empleo, el traslado de los beneficios del crecimiento a la mayoría de la población y el estímulo del sector agropecuario y de la micro y pequeña empresa. Esto no implica, empero, que no existan diferencias apreciables entre ambos proyectos. En efecto, son notables las divergencias en puntos como la atención que el proyecto de ARENA presta a los salvadoreños residentes en el exterior o al sector construcción, o bien la preocupación del FMLN en aspectos como la protección al consumidor y el desarrollo local. Empero, uno de los puntos más relevantes es el diferente tratamiento que se ofrece al sistema financiero. El proyecto de ARENA parte del hecho de que el camino recorrido hasta ahora no necesita rectificaciones, lo cual se evidencia, por ejemplo, en el reconocimiento de que la alianza para el trabajo se desarrollaría "fortaleciendo la reforma fiscal y financiera" y en la ausencia de propuestas concretas para lograr la mayor asistencia crediticia que se ofrece en los programas sectoriales.

La propuesta del FMLN-USC contempla la necesidad de reformar el funcionamiento del sistema 
financiero; a diferencia de ARENA, que más bien plantea fortalecerla como medio para transferir los "beneficios del progreso". Inclusive, una de las áreas de política de la propuesta del FMLN-USC está dirigida a reformar el sistema financiero, tal como se reseñó arriba. Esta es una diferencia fundamental entre las dos propuestas y determina el que un futuro gobiemo de ARENA tenga menor margen de maniobra para garantizar suficiente oferta crediticia y así cumplir con sus ofrecimientos. Es importante recordar que los programas sectoriales dirigidos al agro, a la micro y pequeña empresa y a la construcción ofrecen mayores montos de crédito que los que hasta ahora ha proporcionado la banca privatizada.

Otro aspecto que diferencia a las propuestas es el de la desgravación arancelaria. De seguir con la política de reducción de los aranceles que se ha desarrollado desde el primer gobierno de ARENA, muchas empresas industriales y agropecuarias reducirán hasta el mínimo sus posibilidades de sobrevivir. El plan de ARENA no toca directamente este aspecto, pero, por estar incluido en la temática fiscal, es de suponer que lo que se pretende es continuar "fortaleciendo" la desgravación arancelaria. La propuesta del FMLN-USC, en cambio, la incluye dentro de sus políticas hacia el sector agropecuario, aunque sin especificar cuál será la política arancelaria para otros sectores económicos importantes, como la industria, por ejemplo. Un tema que ninguna de las dos propuestas desarrolla con suficiente claridad es el de las necesarias políticas de reconversión productiva que deberían acompañar a las medidas de desgravación arancelaria. A lo sumo, ARENA ofrece "diversificar" la producción del agro y el FMLN-USC, la investigación científica para promover el desarrollo del sector industrial.

La temática de la política cambiaria tampoco recibe la importancia debida, pese a su papel estratégico, tanto para controlar la inflación como para estimular incrementos en la competitividad de la producción exportable. Lamentablemente, ambas medidas suelen ser mutuamente excluyentes. La propuesta del FMLN-USC, aunque propone desarrollar el sector rural, considera mantener el tipo de cambio "estable", mientras se cuente con suficientes divisas, lo cual supone renunciar a incrementar los ingresos y la competitividad del sector agroexportador, pero también mantener la inflación a niveles bajos y proteger los ingresos de los sectores asalariados. En el caso de ARENA, la promoción de las exportaciones, aunque supone diversificar la base exportadora y facilitar el acceso a otros mercados, no refleja cómo se logrará el incremento de la competitividad de los productos salvadoreños, tanto porque no hay referencia al problema cambiario como porque no hay políticas específicas de incorporación de los avances de la ciencia y tecnología a los procesos productivos. A lo más, la política de "apoyo a la productividad" contempla, dentro de la capacitación de los recursos humanos, la promoción de "alianzas tecnológicas entre centros de formación nacionales y del exterior".

En síntesis, los programas de gobierno analizados, pese a provenir de las "extremas", muestran similitudes importantes, especialmente en lo referido a la necesidad de fomentar el crecimiento y el empleo a partir de los sectores productivos. Sin embargo, ninguno aborda con la debida importancia problemas de gran trascendencia, como el sesgo antiexportador de las políticas económicas, la dependencia de las remesas familiares y la articulación de las políticas de reconversión productivas con las demás políticas económicas.

$\mathrm{Al}$ igual que en lo relacionado con el tema económico, en lo que respecta a las políticas sociales las propuestas de ARENA y el FMLN-USC coinciden en muchos puntos, algunos de ellos fundamentales. Tanto el partido oficial como la coalición proponen una reforma del sector salud, una política para extender la cobertura y facilitar el acceso a la vivienda, y sobre la educación coinciden en la necesidad de extenderla, profundizarla y relacionarla más estrechamente con la ciencia y la tecnología. Así, en propuestas tan similares, los errores y debilidades son los mismos: en primer lugar, ninguno de los dos establece una jerarquía de prioridades ni una calendarización para aplicar las políticas sociales que se proponen: todo es igualmente importante e intemporal.

En segundo lugar, las políticas sociales de ambos partidos sobrepasan los límites de las posibilidades económicas del país: proponer una reconstrucción integral de la infraestructura educativa o el acceso, a nivel urbano y rural, a la vivienda son pretensiones desaforadas, irrealizables en un contexto tan pobre y con tantas necesidades como el nuestro. En tercer lugar, tanto Francisco Flores como Facundo Guardado pasan por alto que la participación de la empresa privada en la presta- 
ción de los servicios básicos -en especial por la rapacidad que caracteriza a la primera y por la debilidad de los mecanismos para controlarla-, no necesariamente se traducirá en mayor eficiencia y cobertura, menos aún cuando la elevación de las tarifas sustituiría a la ausencia de infraestructura física como barrera para el acceso a los servicios.

También en lo que a seguridad pública se refiere, las similitudes entre los programas de gobierno de dos fuerza políticas tan disímiles abundan más que las diferencias. Tanto ARENA como el FMLNUSC hacen énfasis en el papel de la Policía Nacional Civil en el control de la delincuencia, proponiendo de la misma manera y casi con las mismas palabras una reforma a la estructura de la institución, a sus estrategias de acción y a su relación con las otras entidades relacionadas con el área de seguridad pública. Ambas fuerzas políticas señalan también la deficiencia de los procesos judiciales y plantean una reformulación de las políticas carcelarias del país. Además, hacen de la información y la participación ciudadana una de las piedras de toque para el combate contra la delincuencia.

Sin embargo, en lo relacionado con el tema de la corrupción gubernamental, las diferencias no podrían estar más a la vista. Mientras la propuesta del FMLN-USC hace especial énfasis en el punto, proponiendo la creación y adopción de códigos e instituciones especializados en el control y supervisión de los funcionarios públicos, así como de un sistema de acceso ciudadano a la información relacionada con el gobierno, en la "Alianza por la seguridad" la probidad del gobierno y sus funcionarios es un tema casi ausente. La explicación de esto trasciende los documentos: mientras la plataforma de Francisco Flores estaría dando continuidad a la actitud de las dos administraciones areneras de limitar el problema de la delincuencia a sus niveles común y medio (para la "Alianza por la seguridad" no parecen existir los delitos de cuello blanco), el FMLN estaría tratando de sacar capital político de los escándalos de comupción y de defraudación financiera acaecidos en los últimos cinco años.

Es grave y preocupante que en el documento de ARENA se dedique un apartado completo a los menores infractores y los jóvenes en situación de riesgo (los que delinquen son los po- bres y los inadaptados, parece ser un supuesto básico de su documento), mientras sólo dedica un par de líneas a la corrupción y el fortalecimiento de las instancias supervisoras del sistema financiero y las empresas de servicios públicos. Tal vez en esto, el partido no quería comprometer a su candidato presidencial con lo que no puede $-y$ tal vez no le convenga - realizar: remover de su administración el parasitismo y aprovechamiento gubernamental de dos décadas.

Por otra parte, de todos los aspectos tratados en las plataformas de ARENA y del FMLN-USC, es en el tema de democratización y participación ciudadana en el que las diferencias saltan más claramente a la vista. Es evidente que mientras la coalición considera el tema de la consolidación de la democracia tan importante como para dedicarle un área entera —el área política-, el partido oficial soslaya la relevancia de la problemática, omitiendo por completo el planteamiento de puntos que la aborden de manera específica. Pero la evasión de este tema por parte de ARENA -que reduce la descentralización al problema de la prestación de servicios básicos y parece proponer que sean los mismos municipios los que tengan que arreglárselas para obtenerlos - no extraña si se tiene en cuenta que tanto el Presidente Calderón Sol como los demás funcionarios areneros no han hecho más en los últimos diez años que vanagloriarse de lo mucho que, gracias a ellos, ha avanzado el sistema político salvadoreño.

Así pues, es positivo el hecho de que en el Plan de Gobierno del FMLN-USC figuren con tanto detalle las propuestas en materia de institucionalización democrática, tanto porque las pro-

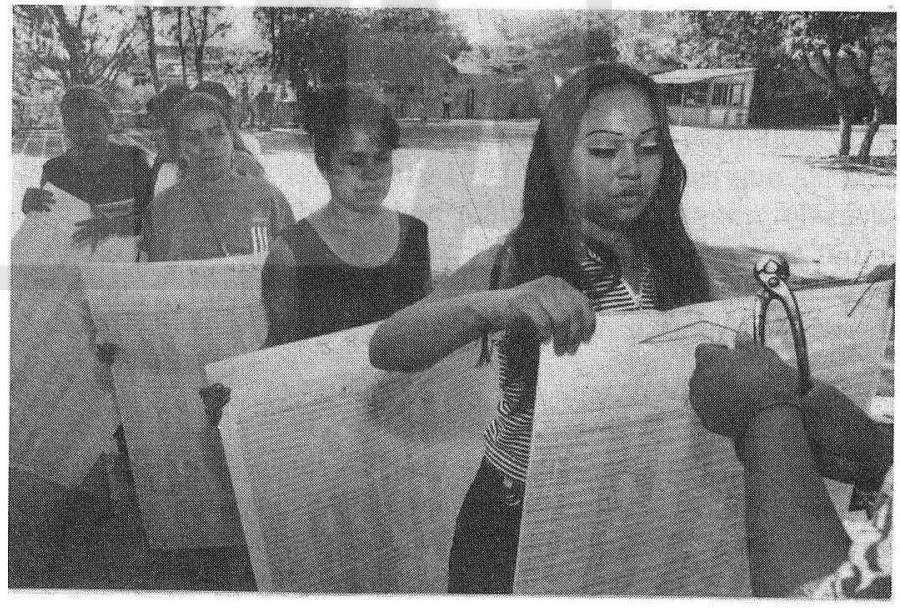


puestas mismas sirven de diagnóstico y denuncian lo mucho que falta por avanzar en ese aspecto contradiciendo lo que el partido gobernante quiere hacer creer con sus discursos y con su actitud-, como porque es alentador que la segunda fuerza política del país parezca tomarse en serio el reto que la mencionada problemática supone.

Respecto a la problemática de género, hay que decir que existe una diferencia sustancial entre ambos proyectos. El componente de género es amplio y abarca muchos sectores dentro de la plataforma del FMLN-USC, mientras que ARENA es más superficial en el desarrollo del tema. Y es que, además del apartado "Promoción de la Mujer" presentado por la coalición, se plantean a lo largo del documento diferentes medidas orientadas al desarrollo y apoyo a las mujeres, incluidas dentro de temas generales como el sistema educativo, el sistema de salud, política habitacional, empleo, sector rural, micro, pequeña y mediana empresa, entre otros.

El plan de gobierno de ARENA, en cambio, clasifica a las mujeres como "grupo vulnerable", y en todos los puntos donde el sector femenino es mencionado, esta caracterización es recurrente. Por lo demás, todo aquello referente a sector rural, micro y pequeña empresa, productividad, empleo, participación politico-social, se aborda separado de las necesidades de las mujeres. Se puede afirmar, pues, que en la plataforma de ARENA se comete el error de encasillar al sector femenino en un estereotipo de personas frágiles, lo cual no permite ver más allá de una mujer madre de familia que debe estar clasificada dentro de un "grupo vulnerable". En conclusión, la visión de género que se transparenta en el documento de ARENA es aún muy raquítica comparada con la complejidad de la problemática que hoy en día aqueja a las mujeres salvadoreñas. Sin duda, la plataforma del FMLN-USC es bastante más propositiva y tiene más conciencia de la realidad actual de las mujeres que la de ARENA. Pero, como quiera que sea, es alentador que dentro de los planes de gobierno propuestos para los próximos cinco años de gestión, los problemas de las mujeres formen parte de los objetivos del futuro gobierno. 